Illinois State University

ISU ReD: Research and eData

Theses and Dissertations

$3-31-2021$

\title{
People Who Mistake Dogma For Reason: Development And Validation Of The Pseudo-Rationalism Scale
}

Han Wool Jung

Illinois State University, jhw2@naver.com

Follow this and additional works at: https://ir.library.illinoisstate.edu/etd

Part of the Social Psychology Commons

\section{Recommended Citation}

Jung, Han Wool, "People Who Mistake Dogma For Reason: Development And Validation Of The PseudoRationalism Scale" (2021). Theses and Dissertations. 1380.

https://ir.library.illinoisstate.edu/etd/1380

This Thesis is brought to you for free and open access by ISU ReD: Research and eData. It has been accepted for inclusion in Theses and Dissertations by an authorized administrator of ISU ReD: Research and eData. For more information, please contact ISUReD@ilstu.edu. 


\section{PEOPLE WHO MISTAKE DOGMA FOR REASON: DEVELOPMENT AND VALIDATION OF THE PSEUDO-RATIONALISM SCALE}

\section{HAN W. JUNG}

30 Pages

Pseudo-rationalism is defined as a distorted ideology that believes reason or rationality is superior to other components of minds (especially, emotion), which may lead to the overestimation of one's own rational ability and underestimation of others' rationality. Such a trait would be similar to rigidity or closed-mindedness measurable with other existing scales, but also is expected to have some distinctive characteristics compared to them because it is based on a certain myth in terms of reason. Also, if the psychological trait of pseudo-rationalism exists, it is anticipated as a byproduct of a certain egocentric world-view represented by naïve realism. This study aimed to develop and validate an empirically measurable scale of pseudo-rationalism. After the initial items were created based on the structured definition of the concept of pseudorationalism, exploratory factor analysis was conducted to evaluate its construct validity. In addition to the reliability estimate, the convergent and discriminant validity of this new construct was tested by comparing it with other similar scales (e.g., dogmatism, perspective taking, and intellectual humility).

KEYWORDS: pseudo-rationalism; empathy; dogmatism; perspective taking; intellectual humility; naïve realism 


\title{
PEOPLE WHO MISTAKE DOGMA FOR REASON: DEVELOPMENT AND VALIDATION OF THE PSEUDO-RATIONALISM SCALE
}

HAN W. JUNG

\author{
A Thesis Submitted in Partial \\ Fulfillment of the Requirements \\ for the Degree of \\ MASTER OF SCIENCE \\ Department of Psychology \\ ILLINOIS STATE UNIVERSITY
}


(C) 2021 Han W. Jung 


\section{PEOPLE WHO MISTAKE DOGMA FOR REASON: DEVELOPMENT AND VALIDATION OF THE PSEUDO-RATIONALISM SCALE}

HAN W. JUNG

COMMITTEE MEMBERS:

Eros DeSouza, Chair

Joseph Hilgard 


\section{ACKNOWLEDGMENTS}

First of all, I appreciate my supervisors, Dr. Eros DeSouza and Dr. Joseph Hilgard, for their long endurance and assistance that let me complete this thesis and graduate. Especially, thank you very much to Dr. Joseph Hilgard who provided funding for this study. I also appreciate my colleagues in the IOS sequence who have helped to test the survey and given lots of precious feedback.

H. W. J. 


\section{CONTENTS}

Page

ACKNOWLEDGMENTS

$\begin{array}{ll}\text { CONTENTS } & \text { ii }\end{array}$

TABLES

CHAPTER I: WHAT IS PSEUDO-RATIONALISM? 1

What is Pseudo-Rationalism? 3

CHAPTER II: THE PSYCHOLOGY OF PSEUDO-RATIONALISM 5

The Tenets of Pseudo-Rationalism

Fundamentals $\quad 5$

Cognitive Features $\quad 5$

The Dichotomy Between Reason and Emotion 6

$\begin{array}{ll}\text { Illusory Intellectual Superiority } & 7\end{array}$

Theoretical Background: Naïve Realism $\quad 8$

False Consensus Effect $\quad 9$

$\begin{array}{ll}\text { Bias Blind Spot } & 10\end{array}$

CHAPTER III: VALIDATION PROCESS 12

$\begin{array}{ll}\text { Initial Item Selection } & 13\end{array}$

Validation Study 13

$\begin{array}{ll}\text { Participants } & 13\end{array}$

$\begin{array}{ll}\text { Item Factor Analysis } & 13\end{array}$

$\begin{array}{ll}\text { Comparison with Similar Scales } & 14\end{array}$

$\begin{array}{ll}\text { Dogmatism (DOG) } & 14\end{array}$ 
$\begin{array}{ll}\text { Perspective taking (PT) } & 14\end{array}$

$\begin{array}{ll}\text { Intellectual humility (IH) } & 14\end{array}$

$\begin{array}{ll}\text { Procedure } & 15\end{array}$

CHAPTER IV: RESULTS 16

$\begin{array}{ll}\text { Item Finalization } & 16\end{array}$

$\begin{array}{ll}\text { Exploratory Factor Analysis } & 17\end{array}$

$\begin{array}{ll}\text { Correlations with Other Variables } & 18\end{array}$

$\begin{array}{lr}\text { CHAPTER V: DISCUSSION } & 20\end{array}$

$\begin{array}{ll}\text { REFERENCES } & 23\end{array}$

APPENDIX: INITIAL ITEMS AND PRELIMINARY ANALYSIS 27 


\section{TABLES}

Table $\quad$ Page

1. Factor Loadings of the Finalized Items $\quad 18$

2. Descriptive Statistics and Correlation Matrix of the Measures 19 


\section{CHAPTER I: WHAT IS PSEUDO-RATIONALISM?}

"Science is in the realm of reason, not sensibility." said Suk-Chun Ryu, a former professor in the Department of Sociology at Yonsei University, Republic of Korea, while defending the remarks he made in the class that he called the comfort women, the sexual slaves forced by the Japan Imperial, as 'voluntary prostitution' and the sexual harassment remarks he made against female students in this process (Kim, 2019). His view of history in advocating for the atrocities of imperialism and the lack of awareness of women's rights in itself caused intense controversy in Korean society, but the more serious was after such remarks. Under the controversy, he focused on justifying himself and even denounced his opponents. The quote above is illustrative: It implies that he just made a level-headed judgment by logical reasoning (although it might be uncomfortable to someone) and the counterforces are rather irrationally reproaching him based on the emotional judgment. Although he is protesting that he actually made cool and 'right' judgments whereas the opponents are distorting the real intention of his remarks to drive them into a sort of hate speeches, he seems not to be realizing that such a protest per se refers to the emotional judgment to rationalize his extreme form of beliefs.

Similar ideas can be found not only in Korea but all over the world today. For example, Ben Shapiro (2016), a famous right-wing commentator, once left the phrase "Facts don't care about your feelings": This can be seen as a very similar value to the case discussed above, considering that it also pursues the so-called 'rationality' that may make people uncomfortable. Interesting is that he evidenced by himself that such an attitude was actually derived from emotional justification, not the true rational judgment: In a recent interview with $\mathrm{BBC}$, he became the center of controversy for ending the conversation halfway with fury just because he did not like the questions being posed (Haltiwanger, 2019). Such instances, in practice, may 
exemplify today's rampant justification of heartlessness and counter-empathy: The claim of selfrationality, ironically, now became one of the most common attitudes among extremists. Namely, such kinds of values are not only linked to antisocial or extremist arguments but also contributing to even more justify or solidify such arguments or attitudes. Now we have to delve into the origin of such values rather than focusing only on their arguments, which would make us stuck to the reiteration of pointless superficial discourses. Stop criticizing every glamorized dogma one by one, but let's find out why they mistake dogma for reason from now. Why are they eager to justify the dogma, which mars social empathy and creates needless social conflicts? What is the essence of such values? They pretend to be rational, but not really are they. Their myth of 'reason' is, wherever its motives, by itself the manifestation of their unreasonable bias, which is sometimes exploited as the means of justification of the lack of empathy, as in the case of Suk-Chun Ryu above. In other words, their pretense regarding 'cold-heartedness' is rather deemed to be an emotional motive to coax themselves and others, which would compensate for their lack of empathy, i.e., another byproduct of unintelligence.

Like this, the belief system that regards one's rigidity as rationality and overestimates one's rational abilities is often called pseudo-rationalism. Despite the sporadic discussions erstwhile about its concept and implications, however, little is known about the psychological features of pseudo-rationalism yet. Hence, my goal is to identify the presence and nature of this trait. As a starting point, this study aims to develop an instrument to empirically 'measure' such a character and check whether such a measured trait is congruent with the features covered in the existing social-philosophical discussion or the similar psychological theories to it. That way, we would be able to start the full-fledged research in terms of the psychological implications of the pseudo-rationalism and illusory intellectual superiority. 


\section{What is Pseudo-Rationalism?}

Popper (1945) represents the attempts to define the concept and characteristics of pseudorationalism. He argued that the true rationalism and pseudo-rationalism should not only be clearly distinguished but also be considered as the complete antipode of each other. According to him, the true rationalism should know one's own limitations, how much one makes mistakes in judgments, and how much we are indebted to others with regards to knowledge. Therefore, the real rationalists understand that we cannot expect the impossible from reason, just trying to be clearer than before rather than expect something clear. In contrast, pseudo-rationalism refers to the 'immodest belief' of one's intellectual superiority, pursuing certainty or authority. Such an ideology that seeks absolute and immaculate truth is, although often taking the place of reason, by itself diametrically opposed to rationalism.

Popper's (1945) argument demonstrated a clear insight into the dangers of pseudoscientific dogma that is not based on empirical evidence, although, paradoxically, he rather has usually targeted to the scientific empiricism per se (i.e., he has been skeptical about the scientific methodology of rational verification). In practice, since his argument, the term 'pseudo-rationalism' has often been utilized in the philosophical field as an expression of skepticism to the belief that empirical studies or experiments can absolutely enhance rationality (See Donohue, 2017; Nemeth, 1991). Therefore, such a term or argument is basically derived from the discussion regarding the philosophy of science, whose contextual meaning is somewhat unclear, and questions remain as to whether this is a universal propensity applicable to most laypeople. In this study, however, I will continue talking under the premise that the pseudorationalism that Popper (1945) defined can also be the lay cognitive tendency universally existent among people. That is, some people (even if they are not philosophers or scientists) tend 
to overestimate their so-called reasoning ability more than others do, and such tendency would sometimes make them intensify the dogmatic attitudes about their current beliefs or derogate others' judgments different from their own as irrational. 


\section{CHAPTER II: THE PSYCHOLOGY OF PSEUDO-RATIONALISM \\ The Tenets of Pseudo-Rationalism}

If there is a psychologically definable concept of pseudo-rationalism, what characteristics would represent such a tendency? The following is the nature of pseudo-rationalism defined in this study or the traits predicted to be observed among pseudo-rationalists.

\section{Fundamentals}

- Overestimation of the superiority of reason or logical reasoning, especially compared to feelings or intuitions

- Overestimation of one's own rational abilities, especially compared to others

- Ignorance of the uncertainty of the world and the primordial limitations in our understandings of the world

- The projection of such a tendency to other people that considers others as emotional and irrational

\section{Cognitive Features}

- Make a conclusive presumption based on limited evidence

- Ignore or gloss over the limitations in evidence with assumptions from one's ideology or preexisting beliefs

- Prescribe one's conclusions or beliefs as absolutely true or completely rational, rejecting the possibility of emotional influence in one's own beliefs 
- Assume those who have reached conclusions different or contrary to their own as irrational or emotional

However, caution is that there are already lots of psychological instruments measuring those that are similar to such features, maybe representing the jingle-jangle fallacy. Such features are not very different from closed-mindedness or rigidity: specifically, dogmatism (Rokeach, 1954; blind faith in certain opinions or tenets), (lack of) perspective taking (understanding of other people's positions or perspectives), or (lack of) intellectual humility (modest or humble view of one's intellectual ability). These concepts are psychologically consensual, at least to some extent, with the existing validated measures (dogmatism - Altemeyer, 2002; perspective taking - Davis, 1980; intellectual humility - Leary et al., 2017). Nevertheless, I believe the development of this new measure can be relevant because although they may share some domain, it also has some distinct features from the existing measures mostly divided into the two aspects following:

\section{The Dichotomy Between Reason and Emotion}

It is the common myth regarding human cognition among laypeople (or popular psychologists) that reason and emotion are conflicting forces. Such myth, of course, has no scientific basis: These two are, at most, orthogonal to each other (Ciarrochi et al., 2000), or even the opposite may be true. For example, Côté and Miners (2006) reported the positive association between general cognitive intelligence and emotional intelligence. Nevertheless, such a dichotomy is well-observable in our daily life: For instance, we often use brain/head and heart as the confronting terms. This seems even worse in South Korea: The Korean words e-sung (which refers to reason) and gam-sung (which refers to emotion or sensibility) are commonly 
used as antonyms of each other, probably because of the framing effect that arises from their nuances. As seen in such word pairs, this viewpoint seems like a quite traditional one, but it may have become even severe in recent years because of the current fad of the Myers-Briggs Type Indicator (MBTI; Myers, 1998): In particular, today’s younger generations seem to be consuming MBTI as a powerful Internet meme, uncritically accepting it in overall communications or interpersonal relationships (Essig, 2014; Park, 2020). The dichotomous distinction between thinking and feeling that this trait theory claims are being indiscriminately consumed by many people, even though no scientific evidence supports this theory (Grant, 2013; Thyer \& Pignotti, 2015).

\section{Illusory Intellectual Superiority}

It hypothesizes that when such a dichotomy between reason and emotion polarizes, it develops into the prejudice based on self-centeredness, which eventually leads to the superiority complex and derogation/aggression towards others such as 'I am rational, you are foolish.' Although nothing has been clear about it yet, I predict this from some clues. For instance, the analogies between rational choices and 'should be' and between emotional choices and 'want to $b e^{\prime}$ implies the propensity that only rational decisions can be the right decisions, whereas emotional decisions are a kind of impulsive ones. We can see some expressions that deride the emotions and emotional judgments, e.g., touchy-feely. There is also a similar expression to it in Korea: Gam-sung-par-ee, which literally means emotion sellers, refers to the pejorative term of emotional judgments or those who make (or in their words, misuse) such judgments. If some 'extreme reason-supremacists' use such words as an expression of mockery or aggression to others, we may have to deal with such a phenomenon as a typical form of prejudice. 
Nevertheless, even if such a concept exists with distinctive features from the existing one of closed-mindedness, nothing can be said yet about its psychological identity or mechanism. Is it a natural (i.e., intrinsic) trait, a sort of self-enhancing defense mechanism to compensate for the inferiority complex, or derived from the complex dynamics including them? Now we can only see the phenomenon itself without well-established theories. However, we can predict something regarding the origin of this characteristic: Social psychologists have accumulated many studies with regards to people's closed-mindedness and self-centered world views, which also includes this trait. According to them, such tendencies begin from the distorted fundamental belief that one is perceiving the world accurately and objectively, which eventually creates a series of cognitive bias that believe oneself and one's world view are thoroughly rational or the 'metabias' that perceive even such biases biasedly, resulting in the ironic overconfidence of one's own objectivity and rationality.

\section{Theoretical Background: Naïve Realism}

Naïve realism refers to the tendency that people believe that they are seeing the world objectively whereas those who oppose them are senseless or biased (Ward et al., 1997). They stated that naïve realism has three important tenets: the belief that one is perceiving the world impartially and unbiasedly, the expectation that others will make the same conclusions as oneself if they have the same information and the ability to rationally interpret it, and the assumption that those who do not make the same conclusions would be ignorant, irrational, or biased. Such a belief represents the propensity that people see their surroundings 'as it is' to secure the structure of their scheme or outlook, which rather triggers umpteen self-centered biases. Although it is 
hard to directly measure such a tendency per se, we can figure out the existence of naïve realism from its diverse cognitive outgrowths, which are typically divided into two traits following:

\section{False Consensus Effect}

The false consensus effect refers to the phenomenon in which people believe the opinions they hold are universal and most of the other people would have the same opinions as to their own. This is first discovered by Ross et al.'s (1977) famous experiment. The participants were asked whether they could walk around the campus while putting on a big board sign written as 'Eat at Joe's': Those who accepted it tended to believe that most other participants would also do so, whereas those who rejected it tended to believe that most others would also reject it. Dobelli (2013) said that in this experiment, those who answered yes described those who answered no as 'stuck up and humorless,' whereas those who answered no described those who answered yes as 'idiots and attention seekers': Namely, the participants tended to derogate those who made different decisions from their own.

Although the false consensus effect has originally been studied as a universal tendency equally applicable to all ordinary people, some individual differences in this effect have been known, especially in terms of political orientations and prejudice. For instance, Rabinowitz et al. (2016) reported that conservatives tended more to believe that most other people will agree with themselves regarding the issue of child vaccination, whereas liberals showed the 'illusion of uniqueness' that believes others will not agree with themselves (i.e., the reverse consensus effect). Wojcieszak (2008) reported that the neo-Nazis, especially those who participate in the online groups, are likely to have stronger false consensus biases compared to environmentalist groups. 


\section{Bias Blind Spot}

The bias blind spot is a sort of 'bias about bias.' Even after being informed about certain cognitive biases, people tend to believe that such biases do not pertain to themselves but only the matter of others, and therefore, underestimate their own extent of bias and overestimate others' extent of bias (Pronin et al., 2002). This is considered as a 'meta-bias' that people cannot recognize their own biased views; their ignorance regarding bias is not one-dimensional but stratified and comprehensive. More interesting is that those who are more biased are likely to believe that they are not biased but objective: For instance, West and Eaton (2019) found that people who are more prejudiced tend to claim more that they are not prejudiced, but rather, egalitarian with regard to both racism and sexism. This is theoretically based on the DunningKruger effect which indicates that cognitively incompetent people rather overestimate their own competency (Dunning, 2011), suggesting the contradictory (and intertangled) nature of the relationship between cognition and metacognition. Similarly, Pronin and Kugler (2007) also attempted to link bias blind spot to introspection illusion: They demonstrated that people are likely to believe they are introspecting themselves well even when making judgments regarding their own biases.

We can find that most of the features of naïve realism and its descendants are in line with pseudo-rationalism: in particular, the belief that one's own judgments would be rational, the attitudes that assume those with different opinions as irrational and derogate them, and the 'total ignorance' that stems from the lack of the true introspection of oneself. This is why I expect that pseudo-rationalism will be included in the same framework as naïve realism, if it exists. Being evidenced, pseudo-rationalism will be considered as a byproduct derived from the mechanism of 
self-centered dogma and the rationalization of it. I anticipate that it will also contribute to the efficiency of psychometrics because it can substitute the current complex measurement of naïve realism largely based on the cognitive assessment with a simple short scale. 


\section{CHAPTER III: VALIDATION PROCESS}

The validation process of pseudo-rationalism would be based on the suggestion of Flake et al. (2017). They proposed the three main components of validity: substantive, structural, and external. The substantive validity represents the qualitative analyses to verify whether the developing scale is in line with the concept that is aimed to be measured, including literature review, conceptualization, expert review, or other verifications regarding content relevance. The structural validity refers to the quantitative measurement of the psychometric properties of the scale and includes reliability check, factor analysis, or item analysis. In the external phase, the developing scale is compared with other related constructs or criteria, being tested whether the scale is well-convergent with and/or discriminant from other measures, predicts the relevant criteria well, or successfully discriminates multiple known-groups.

In this validation process, the item conceptualization and organization based on the definition of pseudo-rationalism proposed in the previous chapter would cover the substantive validity. It includes the review and confirmation of my supervisors. The initial scale items made through this process would be sorted out through the exploratory factor analysis to create the final scale. The structural and psychometric properties would be confirmed in this process. Also, the external validity would be tested by comparing this new scale with existing similar scales. Ideally, the correlations between the pseudo-rationalism scale and other scales would show both convergent validity (i.e., the correlations between pseudo-rationalism and the similar scales) and discriminant validity (i.e., how much uniqueness this new pseudo-rationalism scale has compared to the existing scales). 


\section{Initial Item Selection}

The initial items were created and organized based on the conceptualized characteristics of pseudo-rationalism discussed above and aims to assess the various natures pseudo-rationalism is expected to have in a balanced manner. They were measured with a 7-point scale from 1 (strongly disagree) to 7 (strongly agree). These initial items consist of 27 items (see Appendix).

\section{Validation Study}

The purpose of this study was to develop and finalize the items, test the structural and external validity of the construct, and confirm the psychometric properties of this scale. This study also compared this scale with other scales that are based on similar concepts, conjugating correlation analysis for testing convergent validity.

\section{Participants}

One-hundred and seventy-five participants, 18 years of age or older, were recruited from Prolific.co. However, 26 responses were eliminated from the analysis because they did not pass the attention check questions. Of the valid 149 responses, $63 \%$ were men and $34 \%$ were women; $79 \%$ were White and $14 \%$ were Hispanic. The average age was $26.6(S D=8.88)$, and $84 \%$ of them aged 32 or less.

\section{Item Factor Analysis}

The factor structure of the finally selected items was identified through the exploratory factor analysis with the maximum likelihood method. The sub-factors of this scale will be determined in this process. The psychometric properties of this scale (e.g., Cronbach's $\alpha$ ) were also estimated along with this process. 


\section{Comparison with Similar Scales}

This scale was compared with three other measures: dogmatism, perspective taking, and intellectual humility.

Dogmatism (DOG). Altemeyer's (2002) DOG scale is a representative measure of the rigid and authoritarian personality, composed of 20 items with about .90 of Cronbach's $\alpha$. He reported that those who answered that God chose every word and the Bible is free of any errors tended to have $65 \%$ higher DOG score along with $62 \%$ higher right-wing authoritarianism (RWA) score and 73\% higher religious fundamentalism score, providing evidence for the external validity of this measure. In that study, furthermore, among the initial 'true believers' of God and the Bible, those who changed their opinions after facing the challenging evidence had significantly lower DOG score than those who still insisted the absoluteness of them after then. This scale consists of a 9-point scale from 1 (strongly disagree) to 9 (strongly agree).

Perspective taking (PT). The perspective taking (PT), a subscale of Davis' (1980, 1983) Interpersonal Reactivity Index (IRI), was used. This scale measures how well people understand others' perspectives and predict the social consequences of their behaviors or attitudes towards others. Davis (1980) reported the whole IRI's internal consistency of .71 .77 and test-retest reliability of $.62 \sim .71$. Davis $(1983)$ found that those who scored high on the perspective taking tend to have low negative masculinity ( $r=-.28$ for females and -.30 for males) and negative verbal-aggressive femininity ( $r=-.25$ for females and -.19 for males), high self-esteem $(r=.20$

$\sim .26$ for females and $.20 \sim .25$ for males $)$, and slightly high intelligence among women $(r=.07$

.13). This subscale consists of 7 items with a 5-point scale from 1 to 5 .

Intellectual humility (IH). Leary et al.’s (2017) 6-item scale of intellectual humility aims to measure the humbleness in intellectual aspects. With the Cronbach's $\alpha$ of .73 .82, this 
scale was positively related to open-mindedness $(r=.43)$, curiosity $(r=.27)$, autonomy $(r=.31)$, and courage $(r=.30)$, whereas negatively connected to dogmatism $(r=-.49$ with the DOG scale), ambiguity avoidance $(r=-.32)$, and self-righteousness $(r=-.35)$. Also, in this research, those with high intellectual humility tended to be stable or consistent when rating other people's attitudes or capacity, regardless of the ratees' political or social orientations. This scale consists of a 5-point scale from 1 (not at all like me) to 5 (very well like me).

To check the convergent validity of pseudo-rationalism, the correlations between the scales above and the finalized pseudo-rationalism scale were reported. As explained, the successful development of the pseudo-rationalism scale should have both stable associations with similar scales and distinctive characteristics from them. The convergent validity would be confirmed if the new scale has sufficient correlations with the three existing scales. The discriminant validity would be confirmed if the correlations of pseudo-rationalism with the existing scales are not excessively high or considerably smaller than the correlations between the three existing scales.

\section{Procedure}

Each participant, recruited from Prolific.co, got $\$ 1.10$ for compensation. They completed an online Qualtrics survey, which took about 10-15 minutes. First, they were told about the information about the study (e.g., purpose of study, compensation, benefits or risks expected, confidentiality, etc.), and then they gave their consent. Second, they were asked to answer the initial scale items of pseudo-rationalism and then complete the DOG, PT, and IH. There were two attention check questions in the middle of the questions, and those who did not make appropriate answers to these questions were excluded from the analyses. After the survey was done, they were redirected to Prolific.co again to get compensated. 


\section{CHAPTER IV: RESULTS}

\section{Item Finalization}

Before conducting the main factor analysis, 12 out of 27 initial items were excluded and 15 were finally selected through the preliminary analysis. This analysis included a few more strategies in addition to the initial factor analysis for the screening of inappropriate items. First, I excluded some items based on the item-total correlations of each item. Gerbing and Anderson (1988) described that the item-total correlations have been widely used for initial scale development because it can be one of the best ways to see the constructs for unidimensional assessment. Although there are no consented cutoff scores for item-total correlations, Nunnally and Bernstein (1994) said that the corrected item-total correlations should be at least .3. Second, I will verify whether the pairs of conflicting items (i.e., sets of one straight-coded item and one reverse-coded item indicating the diametrically opposite statements) are reporting consistent correlations with each other. According to Weijters and Baumgartner (2012), reverse-coded items describing the opposite of the original items can be categorized as the 'polar opposite' items, and although adopting such items can have some merits, these items can also increase the item inconsistency. If the pairs of items reported low correlations and there were no suitable alternative explanations for them, such item pairs were regarded to be derived from the misresponse and excluded. Finally, a preliminary exploratory factor analysis was conducted to figure out the items with low communalities. See Appendix for more details regarding the justification, criteria, and process of the preliminary analysis. 


\section{Exploratory Factor Analysis}

The exploratory factor analysis using a maximum likelihood method was conducted to determine the structure of this measure. Although three initial eigenvalues greater than 1 were extracted, both Velicer's MAP test and the Parallel Analysis for the principal components analysis recommended a two-factor solution. As I assume the correlation between factors, I used the Promax oblique rotation to interpret the factor structure. The extracted two factors with this rotation created the sums of squared loadings from 3.57 to 4.41 . See Table 1 for the factor loadings of each item. This exploratory analysis seems to be well-supporting the two-factor structure, suggesting the first factor of $\alpha=.85$ and the second factor of $\alpha=.80$, which are correlated with each other at $r=.51$. I interpreted that the second factor refers to the individualor intrapersonal-level pseudo-rationalism (i.e., endorsement of the personal belief regarding rational judgments) and the first factor refers to the social- or interpersonal-level pseudorationalism (i.e., blaming other people's judgments or aggressiveness). 


\begin{tabular}{|c|c|c|}
\hline & \multicolumn{2}{|c|}{ Factor } \\
\hline & 1 & \\
\hline & (social) & (individual) \\
\hline People make stupid decisions when they get too emotional. & .80 & \\
\hline To make the best decisions, you should be purely logical. & .26 & .47 \\
\hline My decisions are rarely influenced by my emotions. & & .44 \\
\hline Too many people are easily influenced by their feelings. & .84 & -.23 \\
\hline Most people don't consider the facts when making up their mind. & .60 & \\
\hline More people should try to keep their emotions out of their decisions. & .72 & \\
\hline People get foolish when they are driven by their emotions. & .74 & \\
\hline People make bad decisions when they get emotional. & .70 & \\
\hline Society would be better off if people weren't so emotional. & & .74 \\
\hline Society should make dispassionate decisions. & & .50 \\
\hline People who value emotion above all else are ruining society today. & & .52 \\
\hline People call you "offensive" when you're just trying to say the facts. & .42 & \\
\hline You can have emotions and be rational at the same time. $(\mathrm{R})$ & -.33 & .71 \\
\hline Our emotions make us wise. $(\mathrm{R})$ & & .54 \\
\hline Wisdom does not necessarily come from logic. (R) & & .46 \\
\hline
\end{tabular}

Note: (R) indicates reverse-coded items. Loadings with absolute values less than 2 were omitted.

Table 1. Factor Loadings of the Finalized Items

\section{Correlations with Other Variables}

See Table 2 for the correlation matrix for the variables measured in this study, including descriptive statistics. It seems that discriminant validity of the new pseudo-rationalism scale was confirmed because it has relatively lower correlations with PT, IH, and DOG compared to the correlations between PT, IH, and DOG themselves. However, the correlations with intellectual humility and dogmatism were measured lower than expected: Pseudo-rationalism was only 
marginally correlated with intellectual humility and not correlated with dogmatism. Looking at the subscales (Factors 1 and 2), whereas Factor 2 (individual) was significantly correlated with all the three scales (PT: $r=-.25$, IH: $r=-.24$, DOG: $r=.23$, all $p \mathrm{~s}<.05$ ), Factor 1 (social) was only marginally correlated with the perspective taking $(r=-.15, p=.066)$ but not with others (IH: $r=-.03, p>.10$; DOG: $r=-.08, p>.10)$. This indicates that unlike the individual subscale, social subscale may have extremely low (or even lack) convergent validity.

\begin{tabular}{ccccc}
\hline & PR & PT & IH & DOG \\
\hline $\begin{array}{c}\text { Pseudo-rationalism } \\
\text { (PR) }\end{array}$ & .86 & & \\
Perspective taking & $-.23^{*}$ & .82 & & \\
$(\mathrm{PT})$ & & & & \\
Intellectual Humility & $-.14^{\dagger}$ & $.26^{*}$ & .76 & .88 \\
$(\mathrm{IH})$ & & & & \\
Dogmatism & .10 & $-.20^{*}$ & $-.44^{* *}$ & \\
$(\mathrm{DOG})$ & & & 3.75 \\
$M$ & 4.09 & 3.46 & 0.58 & 1.00 \\
\hline
\end{tabular}

Note: Italicized are Cronbach's $\alpha$.

${ }^{\dagger} p<.10, * p<.05, * * p<.001$.

Table 2. Descriptive Statistics and Correlation Matrix of the Measures 


\section{CHAPTER V: DISCUSSION}

This study has been a novel challenge to develop a new psychological concept that may broaden our understanding of the fundamentals of people's social behavior. Overall, I believe this scale could reveal enough potentials to be a stable psychometric construct. This study, as I first aimed to, could show some evidence for the validity of this new scale: To be specific, this study demonstrated that 1) the psychological concept of pseudo-rationalism exists as a measurable form, 2) such a measure can be established in a reliable and well-constructed state, and 3) such a construct relates, at least slightly, to other conceptually similar measures. Such validity evidence can enhance the feasibility of my theoretical assumption that this concept can be considered as a sort of 'meta-bias' that stems from the more fundamental bias such as naïve realism. Also, it shows the potential for this scale to be used to predict the primordial dark-side traits of human beings, often expressed as 'ignorance of ignorance,' and further, the process that such fundamentals develop into the rigid ideology or social extremity.

However, with this one study alone, which is by default preliminary, clear limitations exist to confirm the validity or argue that this scale was developed perfectly. The biggest issue is how to interpret the low (or perhaps, lack of) correlations of this new construct with the existing measures. The most optimistic would be that this scale can be an original construct, which can cover the areas that the current measures have not covered. Although this scale has a form of self-report, it seems relatively free from social desirability, considering that it reported higher mean score compared to dogmatism (pseudo-rationalism: 4.09 in 1 7 scale, dogmatism: 3.75 in 1 9 scale). Therefore, it may show some predictive ability that the existing measures could not have. However, the diametrically opposite explanation is also possible: Unlike my hypothesis that this measure can be a basis of various forms of rigidity or social extremism, this scale might 
rather be closer to an individual property because only the individual subscale of pseudorationalism reported stable correlations with other similar scales (i.e., PT, IH, DOG) whereas the social subscale did not. At least, I'm not sure if this scale can explain social extremism more than the existing measures like social dominance orientation (SDO) or right-wing authoritarianism (RWA).

Currently, it is hard to know which of these extremely contrasting expectations are correct. Further studies will be needed to verify the predictive ability of this scale. There are generally three major questions to test in future studies. First, to confirm the relationship with naïve realism that I presented as a theoretical background, we can see whether the measured pseudo-rationalism can predict the descendants of naïve realism, e.g., false consensus effect or bias blind spot. Second, we can figure out the relationships of pseudo-rationalism with the constructs germane to social extremism, e.g., SDO or RWA mentioned above. Finally, we may see how much pseudo-rationalism can explain the actual extreme ideologies (e.g., supporting farright politicians, believing anti-intellectual conspiracy theories), and further, how well it can explain compared to other potential predictors such as SDO, RWA, perspective taking, intellectual humility, dogmatism, openness, agreeableness, etc.

Also, we need to discuss whether this scale is well-structured. Proposing a two-factor model, I named one of them as individual pseudo-rationalism and the other as social pseudorationalism, but this classification may not have a sound basis. When looking into the items, we can see that some items are (statistically) being classified into the individual factor even though they explicitly seem to be in the social factor. Because this study was conducted just as an exploratory analysis, some additional structural investigations such as the confirmatory factor analysis (ideally, with slight revisions of the items) may be needed. The validity of the subscale 
is also a concern: We may have to consider removing all the items in the social dimension if it turns out to be telling nothing.

Furthermore, even if this new measure passes all the analyses above, a question mark still remains on whether this scale can be recognized as a lay cognitive trait that applies to everyone. This study is just data-driven research without sufficient theoretical backgrounds, which can be the biggest limitation, and my theory regarding the conceptual basis of pseudo-rationalism seems somewhat unsystematic. It will take quite a long time for the conceptual significance of this scale to be recognized, and even more so for me, a novice researcher who still has lots of room for progress.

The last thing to consider is the difference in cultural backgrounds. Although the research questions in this study mostly have derived from Korean cases, the collected data consists mostly of American participants (see Prolific, 2021); therefore, investigating Koreans will also be needed to verify whether this concept is also applicable to the group that I first aimed to. Whether it is revealed to be a common trait that generally applies to all people, or whether it reveals distinct cultural differences, I expect that they would both be interesting. 


\section{REFERENCES}

Altemeyer, B. (2002). Dogmatic behavior among students: Testing a new measure of dogmatism. The Journal of Social Psychology, 142(6), 713-721.

Ciarrochi, J. V., Chan, A. Y., \& Caputi, P. (2000). A critical evaluation of the emotional intelligence construct. Personality and Individual differences, 28(3), 539-561.

Côté, S., \& Miners, C. T. (2006). Emotional intelligence, cognitive intelligence, and job performance. Administrative Science Quarterly, 51(1), 1-28.

Davis, M. H. (1980). A multidimensional approach to individual differences in empathy. JSAS Catalog of Selected Documents in Psychology, 10, 85.

Davis, M. H. (1983). Measuring individual differences in empathy: Evidence for a multidimensional approach. Journal of personality and social psychology, 44(1), $113-$ 126.

Dobelli, R. (2013). The art of thinking clearly: better thinking, better decisions. Hachette UK.

Donohue, C. R. (2017). Joseph Agassi from Metaphysics to Politics. In Encouraging Openness (pp. 19-26). Springer, Cham.

Dunning, D. (2011). The Dunning-Kruger effect: On being ignorant of one's own ignorance. In Advances in experimental social psychology (Vol. 44, pp. 247-296). Academic Press.

Essig, T. (2014, September 29). The Mysterious Popularity Of The Meaningless Myers-Briggs (MBTI). Forbes, https://www.forbes.com/sites/toddessig/2014/09/29/the-mysteriouspopularity-of-the-meaningless-myers-briggs-mbti/?sh=75e4a95f1c79

Flake, J. K., Pek, J., \& Hehman, E. (2017). Construct validation in social and personality research: Current practice and recommendations. Social Psychological and Personality Science, 8(4), 370-378. 
Gerbing, D. W., \& Anderson, J. C. (1988). An updated paradigm for scale development incorporating unidimensionality and its assessment. Journal of marketing research, 25(2), 186-192.

Grant, A. (2013, September 18). Goodbye to MBTI, the Fad That Won't Die. Psychology Today, https://www.psychologytoday.com/us/blog/give-and-take/201309/goodbye-mbti-the-fadwon-t-die

Haltiwanger, J. (2019, May 10). Ben Shapiro, a conservative famous for asking people to debate him, stormed out of an interview he didn't like. Business Insider, https://www.businessinsider.com/ben-shapiro-storms-out-of-bbc-interview-2019-5

Kim, J. H. (2019, September 23). Hate speech? Science is the realm of reason, not emotion. Kyunghyang, http://news.khan.co.kr/kh_news/khan_art_view.html?art_id=201909231147001

Leary, M. R., Diebels, K. J., Davisson, E. K., Jongman-Sereno, K. P., Isherwood, J. C., Raimi, K. T., Deffler, S. A., \& Hoyle, R. H. (2017). Cognitive and interpersonal features of intellectual humility. Personality and Social Psychology Bulletin, 43(6), 793-813.

Myers, I. B. (1998). MBTI manual: A guide to the development and use of the Myers-Briggs Type Indicator. Consulting Psychologists Press.

Nemeth, E. (1991). Otto Neurath's utopias - the will to hope. In Rediscovering the Forgotten Vienna Circle (pp. 285-292). Springer, Dordrecht.

Nunnally, J. C., \& Bernstein, I. H. (1994). Psychometric theory (3rd ed.). New York, NY: McGraw Hill. 
Park, N. (2020, June). MBTI Fad in Korea \& Celebrity MBTI Types. Retrieved November 14, 2020, from https://www.creatrip.com/en/blog/7496/MBTI-Fad-in-Korea-CelebrityMBTI-Types

Popper, K. R. (1945). The open society and its enemies. Routledge.

Prolific. (2021). Explore our participant pool demographics. Retrieved March 19, 2021, from https://www.prolific.co/demographics/

Pronin, E., \& Kugler, M. B. (2007). Valuing thoughts, ignoring behavior: The introspection illusion as a source of the bias blind spot. Journal of Experimental Social Psychology, 43(4), 565-578.

Pronin, E., Lin, D. Y., \& Ross, L. (2002). The bias blind spot: Perceptions of bias in self versus others. Personality and Social Psychology Bulletin, 28(3), 369-381.

Rabinowitz, M., Latella, L., Stern, C., \& Jost, J. T. (2016). Beliefs about childhood vaccination in the United States: Political ideology, false consensus, and the illusion of uniqueness. PloS one, 11(7), e0158382.

Rokeach, M. (1954). The nature and meaning of dogmatism. Psychological Review, 61(3), 194204.

Ross, L., Greene, D., \& House, P. (1977). The "false consensus effect": An egocentric bias in social perception and attribution processes. Journal of Experimental Social Psychology, 13(3), 279-301.

Shapiro, B. (2016, February 5). Facts don't care about your feelings. Retrieved November 14, 2020, from https://twitter.com/benshapiro/status/695638866993115136

Thyer, B. A., \& Pignotti, M. G. (2015). Science and Pseudoscience in Social Work Practice. Springer, pp. 49-51. 
Ward, A., Ross, L., Reed, E., Turiel, E., \& Brown, T. (1997). Naive realism in everyday life: Implications for social conflict and misunderstanding. Values and Knowledge, 103-135.

Weijters, B., \& Baumgartner, H. (2012). Misresponse to reversed and negated items in surveys: A review. Journal of Marketing Research, 49(5), 737-747.

West, K., \& Eaton, A. A. (2019). Prejudiced and unaware of it: Evidence for the DunningKruger model in the domains of racism and sexism. Personality and Individual Differences, 146, 111-119.

Wojcieszak, M. (2008). False consensus goes online: Impact of ideologically homogeneous groups on false consensus. Public Opinion Quarterly, 72(4), 781-791. 


\section{APPENDIX: INITIAL ITEMS AND PRELIMINARY ANALYSIS}

The items below are initial items, not the final items. Only the bold items were selected as the final items. See the results section for the properties of the selected items. (R) refers to the reverse-coded items. The scale ranges from 1 (strongly disagree) to 7 (strongly agree).

- PR1: People make stupid decisions when they get too emotional.

- PR2: To make the best decisions, you should be purely logical.

- PR3: To make a good decision, you need to listen to your heart. (R)

- PR4: My decisions are rarely influenced by my emotions.

- PR5: Too many people are easily influenced by their feelings.

- PR6: I'm able to keep my personal feelings out of my decisions.

- PR7: Most people don't consider the facts when making up their mind.

- PR8: More people should try to keep their emotions out of their decisions.

- PR9: I make my judgments based on reason. ${ }^{1}$

- PR10: I make my judgments based on emotions. (R)

- PR11: I behave according to what my brain knows. ${ }^{12}$

- PR12: I behave according to what my heart wants. (R) ${ }^{2}$

- PR13: People get foolish when they are driven by their emotions.

- PR14: People make bad decisions when they get emotional.

- PR15: Society would be better off if people weren't so emotional.

- PR16: Society should make dispassionate decisions.

- PR17: People who value emotion above all else are ruining society today.

- PR18: Every judgment should be based only on the facts. ${ }^{2}$

- PR19: Every judgment should consider people's feelings. (R) ${ }^{2}$

- PR20: We could make more progress on important social issues if people weren't so emotional.

- PR21: People call you "offensive" when you're just trying to say the facts.

- PR22: You can have emotions and be rational at the same time. (R)

- PR23: To be logical is to be heartless. ${ }^{1}$

- PR24: Our emotions make us wise. (R)

- PR25: Wisdom does not necessarily come from logic. (R)

- PR26: I have to understand others' positions, even if they criticize me. (R) ${ }^{1}$

- $\quad$ PR27: Good decisions require considering others' point of view. (R) ${ }^{1}$

${ }^{1}$ : eliminated in the item-total analysis, ${ }^{2}$ : eliminated in the conflicting item analysis. 
To select the items for the final analysis, a series of preliminary analyses was performed. The factor analysis directly conducted without preliminary screening did not generate interesting results: In the initial factor analysis (with maximum likelihood and Promax rotation), among the finally extracted three factors, the first factor consisted of non-reversed items but the second and third factors generally consisted of reversed items. In particular, Factor 1 consisted of PR1, PR5, PR7, PR8, PR11, PR13, PR14, PR18, PR20, and PR21, which were all straight (non-reverse) coded, but Factor 2 consisted of PR3 (R), PR10 (R), and PR12 (R) and Factor 3 consisted of PR22 (R), PR23a , PR26 (R), and PR27 (R). I interpreted that these results should not only be against the initial hypotheses but be the artifact of response bias such as acquiescence and therefore, decided to screen out the inappropriate items prior to the factor analysis to identify the true factor structure, leading to the final results deduced in the main text.

Roughly two screening analyses were performed here. The first one is the analysis of item-total correlations: Although Nunnally and Bernstein (1994) recommended the cutoff of .3 for the corrected item-total correlations, I adopted more relaxed criteria (.25) for reverse-coded items because this study is just exploratory and reverse-coded items tend to have less consistency than non-reversed ones. Based on these twofold criteria (non-reversed items $>.3$, reversed items > .25), several items were eliminated: PR9 (.27), PR11 (.18), PR23 (.15), PR26 (.23), and PR27 (.13). The removed items in this stage were marked as ${ }^{1}$.

Second, if the conflicting items (i.e., pairs of one straight and non-reversed item and one reverse-coded item describing the diametrically opposing statements) are not showing the non-

\footnotetext{
${ }^{a}$ This item was originally designed for reverse coding but actually analyzed with straight coding because the straight coding rather generated comparatively relevant results.
} 
trivial and stable correlations (i.e., $r<.2$ ), they were also eliminated. The pairs of PR11 and PR12 $(r=.00)$ and PR18 and PR19 $(r=.11)$ belonged to it. Although Weijters and Baumgartner (2012) suggested being careful about interpreting inconsistent polar opposite items especially when people are answering negatively on both the non-reversed and reversed items, such tendencies were not observed in this study: Most people tended to be agreeing with both of the opposite items $\left(M_{\mathrm{PR} 11}=5.36, M_{\mathrm{PR} 12}=4.43 ; M_{\mathrm{PR} 18}=3.99, M_{\mathrm{PR} 19}=4.64\right)$. Therefore, these items were regarded as the results of misresponse and eliminated. The items marked as ${ }^{2}$ refer to it. Finally, a preliminary exploratory factor analysis was conducted with the remaining 19 items. Five initial eigenvalues greater than 1 were extracted in this analysis, but both the scree plot and Parallel Analysis recommended a two-factor solution. The table below represents the pattern matrices with two different extraction methods and Promax rotation. The items were eliminated based on the two criteria:

1. Items without reaching the loadings of .3 in at least one factor were eliminated.

2. Items with .3 or more in both factors were eliminated. 


\begin{tabular}{|c|c|c|c|c|}
\hline \multirow[b]{2}{*}{ Factor } & \multicolumn{2}{|c|}{ Maximum Likelihood (ML) } & \multicolumn{2}{|c|}{ Principal Axis (PA) } \\
\hline & 1 (social) & 2 (individual) & 1 (social) & 2 (individual) \\
\hline PR1 & .83 & -.10 & .81 & -.08 \\
\hline PR2 & .24 & .46 & .22 & .48 \\
\hline PR3 (R) & .19 & .28 & .15 & .34 \\
\hline PR4 & .13 & .48 & .12 & .52 \\
\hline PR5 & .87 & -.25 & .91 & -.29 \\
\hline PR6 & .28 & .29 & .30 & .28 \\
\hline PR7 & .62 & -.11 & .62 & -.10 \\
\hline PR8 & .74 & .00 & .74 & .01 \\
\hline PR10 (R) & .21 & .32 & .17 & .39 \\
\hline PR13 & .74 & .06 & .73 & .05 \\
\hline PR14 & .70 & .10 & .66 & .12 \\
\hline PR15 & .09 & .75 & .11 & .72 \\
\hline PR16 & .18 & .48 & .18 & .46 \\
\hline PR17 & .15 & .57 & .21 & .50 \\
\hline PR2O & .47 & .29 & .51 & .25 \\
\hline PR21 & .45 & .06 & .47 & .03 \\
\hline PR22 (R) & -.36 & .70 & -.33 & .66 \\
\hline PR24 (R) & -.06 & .58 & -.10 & .64 \\
\hline PR25 (R) & -.16 & .46 & -.18 & .49 \\
\hline
\end{tabular}

PR3 and PR6 belonged to the first criterion in ML and therefore eliminated. PR10 barely passed the criterion 1 in ML but was also eliminated for more rigorous item selection. Although below the criteria, PR20 also created too high factor loadings in both factors and therefore eliminated, completing the final 15 items. 